\title{
Spectral Characteristics of Plastic Debris in the Beach: Case Study of Makassar Coastal Area
}

\author{
Ahmad Faizal, Shinta Werorilangi and Wasir Samad \\ Department of Marine Sciences, Universitas Hasanuddin, Indonesia.
}

Received: 2018-11-28

Accepted: 2020-03-05

Key words:

plastic debris;

wavelength;

spectral.

Correspondent email:

ahmad.faizal@unhas.ac.id

\begin{abstract}
Plastic debris becomes a global problem that threatens the coastal ecosystems, and the supralittoral area (beach) turns to be a place for plastic debris to accumulate. Data from the United Nations (UN) states that Indonesia is the second plastic debris contributor in world waters. This study aimed to examine the spectral characteristics of plastic debris accumulated on the beach. The data was collected from the coast of Makassar at 3 different stations: Jenneberang River estuary, Losari Beach and Tallo River estuary. The spectral sample was measured using a 4000 A spectroradiometer that works on a wavelength spectrum of $340-1040 \mathrm{~nm}$. The results showed that the optimum value for plastic debris identification in the coastal area at low tide (dry sand) is $450-670 \mathrm{~nm}$ and at high tide (wet sand) is $450-950 \mathrm{~nm}$. This value will be a reference in the remote sensing method, especially multispectral classification in mapping plastic debris found in coastal areas, and will be one solution to effectively mapping plastic debris.
\end{abstract}

\footnotetext{
() 2020 by the authors. Licensee Indonesian Journal of Geography, Indonesia.

This article is an open access article distributed under the terms and conditions of the Creative Commons
}

Attribution(CC BY NC) licensehttps://creativecommons.org/licenses/by-nc/4.0/.

\section{Introduction}

Marine debris is now a global problem that has affected all water bodies, especially the water surface in coastal areas (Gregory, 2009; Pawar et al., 2016; Thevenon et al., 2014). Its influence visibly shows towards the economy, ecology, public health, and environmental aesthetics (Krelling et al., 2017; SCBD-STAP-GEF, 2012). Marine debris pollution is no longer a regional problem but has scaled up into a global or international problem (McIlgorm et al., 2011; van Franeker \& Law, 2015). Marine debris, especially plastic in waters, has transformed into agents that potentially bring toxic chemicals, such as PCBs and heavy metals to humans (Thevenon et al., 2014; Webb et al., 2013). Whilst microplastics, fragmented from larger plastic debris, that are largely invisible to humans, can also accumulate in the food chain (Driedger et al., 2013).

Some time ago, it was estimated that around $10 \%$ of debris has been discharged into the waters (Van Cauwenberghe et al., 2013). Generally, marine debris from various categories (such as plastic, metal, wood, clothing, etc.) accumulates in coastal areas (NOAA, 2015). The main sources of debris in the waters are from recreational activities, wind or storm, illegal dumping, sewage treatment plants, and fishing industry (Driedger et al., 2013).

In 2010, it was predicted that around 4.8 to 12.7 million metric tons of plastic debris had entered the ocean from 192 countries and Indonesia is the second contributor to the sea debris, 1.29 million tons/year after China by 3.53 million tons/year (Jambeck et al., 2015). With regards to this condition, plastic debris pollution will add to a very large environmental and socio-economic problems in Indonesian waters (Driedger et al., 2013).

Marine debris, especially plastic debris in the waters, due to hydro-oceanographic influences were stranded and accu- mulated in the beach including in the coastal city of Makassar (Maulana, 2016). The identification of marine debris has been carried out using traditional survey methods (Driedger et al., 2013), including in South Sulawesi (Maulana, 2016). Another alternative that might be used is to employ the remote sensing method. The identification of objects using this method is generally based on the spectral characteristics of the object, each different material will give a different spectral curve, including plastic debris will give a different reflection curve to the surrounding object (Driedger et al., 2013; Hörig et al., 2001; Pichel et al., 2007). This second alternative enables a relatively cheaper cost and faster time. The study of remote sensing of plastic debris in coastal areas was still experimental. However, several researchers have tried to monitor marine debris in various parts of the world (Aoyama, 2014; Jambeck et al., 2015; Mace, 2012; Veenstra \& Churnside, 2012). This study aimed to examine the spectral characteristics of the plastic debris on the beach.

\section{The Methods}

This research was carried out in coastal areas, especially in the beach of Makassar City, South Sulawesi Province (5.195 S, 119.352 E dan 5.081 S, 119.429 E), at three stations with adequately different characteristics (Figure 1.). All stations were connected to the waterways that come from the city of Makassar that would potentially bring marine debris to the sea: Station 1, estuary of Jeneberang River, represented exposure area and the water influenced by Jeneberang River; station 2, Losari Beach, represented shelter area and the water influenced by the city small canals disembogue along Losari Beach; and station 3, estuary of Tallo River, which represented semi-enclosed area and the water influenced by Paotere Canal and Tallo River. 
The sample analysis was done at the Marine Ecology Laboratory, Marine Sciences Department, Hasanuddin University and the Remote Sensing and Ecology Laboratory Seameo BIOTROP, Bogor.

The spectral identification of plastic debris in the beach refers to the method used by Murphy et al. (2018) and its development with the implementation stages as follows:

a. Sample collection: plastic debris were collected in three transects lines $(25 \times 60 \mathrm{~m})$ at each station during low tide, sampling is only done on land (Figure 2) (Lippiatt et al., 2013). In each transect plastic wastes were collected with a minimum size of $5 \times 5 \mathrm{~cm}$ in a trash bag. From each station, 10 dry samples were selected based on a different form of plastic wastes for spectral analysis (Figure 3 ).

b) Sample Measurement: the spectral value of the sample was measured using the Ocean Optics USB 4000 type spectrometer which works on a wavelength of 340-1040 nm (nanometer). The measurement of each sample was conducted outdoor with sun exposure (Figure 4). The spectral retrieval process involves spectrometers, light sources, optical fibers, and computers. One spectroradiometer part was connected to the light source and the other part was connected to the object being measured. The position of the light source did not directly face the sun but forms an angle of approximately $45^{\circ}$ and 100 millisecond scanning time (Halma, 2008).

c) Spectra Collection: Reflectance values from samples were recorded using a computer equipped with software Ocean Optics Spectra Suite USB-4000. The spectroradiometer used had a wavelength range of 340-1040 nm with spectrometer components including 3648 linear silicon CCD Array elements, solar sources in the field, optical fibers with a diameter of $400 \mu \mathrm{m}$ and a length of 2 meters, and a computer. The measurement steps were as follows:

Dark Calibration, a calibration was taken with a dark spectral technique and a reference. The dark spectral technique was a data spectral retrieval without light and samples, and a reference technique was taking spectral data using a reference from diffuse reflectance standard model WS-1, Ocean Optics USA.

Reference Calibration/Light Calibration: Reference calibration was carried out by allowing light to reach an equilibrium (takes 30 minutes), making sure all cuvettes were clean of dust or dirt and were functioning normally. The integration time is optimized to reach $\sim 80 \%$. The reference data obtained was stored as a reference for sample measurements.

Setting Boxcar: The boxcar settings were adjusted to a value that was approximately the same as the spectral resolution of the spectrometer. When samples were recorded, the boxcar setting was adjusted to simple boxcar filtering which is a specialized case of SavitzkyGolay filtering where the polynomial order was 0 (Halma, 2008) .

Spectral and Integration time measurement: At the time of measurement, one optic fiber section was connected to the light source and the spectrometer, other optic fiber parts were connected to the sample. Spec- tral reflectance of the plastic debris was measured twice, with an integration time of $100 \mathrm{~ms}$ and resulting in 50 scans for each measurement, after which the spectral measurement was averaged

d. Data analysis used numeric data processing devices, the measurement data was classified by eliminating error values and cutting off visible and near-infrared light waves. Furthermore, the data was made into graphical form with smoothing graphs and were statistically analyzed using OneWay Analysis of Variance to evaluate differences of spectral reflectance curves among stations. The spectral reflectance curves were then compared to spectral reflectance of beach sand during dry conditions (occurring during low tide or beach sand which was not affected by tidal-range) and beach sand during wet conditions (occurs during high tide or beach sand which was still affected by tidal rides) by Nolet et al. (2014).

\section{Result and Discussion}

Spectral measurement results of each sample at each station are presented in Figure 5. The average spectral reflectance curve of each sample shows the same reflectance pattern on each wavelength spectrum. Figure 5 shows a tendency of an increase in spectral reflectance curves for each station. At station 1 there is an increase in spectral curves at wavelengths of 500-625 nanometers $(\mathrm{nm})$, at station 2 the tendency of the increase of spectral curves occurs at wavelengths of 470-600 $\mathrm{nm}$ and at station 3 the tendency of the increase spectral curves happen at wavelengths of 450-570 $\mathrm{nm}$. The graph in Figure 5 shows the difference in the amount of data, this is due to noise that occurred when the recording started so the spectral reflectance curve is smaller than $0 \%$, the value is eventually selected and considered as error data and not employed. The measurement of plastic debris spectral reflectance using radiation sourced directly from the sun, which has a high wavelength (> $800 \mathrm{~nm}$ ), was found to have a lot of noise that appears most likely caused by the low primary light intensity at the time of measurement. According Schaepman and Dangel (2000) and Flanigan et al. (2004), noises occur at spectral reflectance recording are due to poor primary light intensity from the sun and so noise comes up and enters. They also stated that the noise is further enhanced as a result of high sample attenuation and making the transmitted light intensity is very poor and thus gets noisy.

The difference in the spectral characteristics of plastic debris at each station is shown in Figure 5. The characteristics of each station are obtained from the average spectral reflectance value of each sample at each station. The average spectral reflectance value of each station shows the similarity of spectral reflectance patterns. The spectral reflectance pattern of each station starts to show an increase in the wavelength of $500 \mathrm{~nm}$ (blue wavelength) and decreases at a wavelength of $800 \mathrm{~nm}$ (Near-infrared wavelength).

Figure 5 denotes the difference in spectral reflectance curves between each sample with the same pattern tendency. The difference in spectral reflectance curves of each object is influenced by several factors; characteristics of object or sample, the amount of light penetration received by objects (Murphy et al., 2018). Plastics found at the study site have different chemical compositions which will give different reflectance, plastic debris consists of several types; polyeth- 


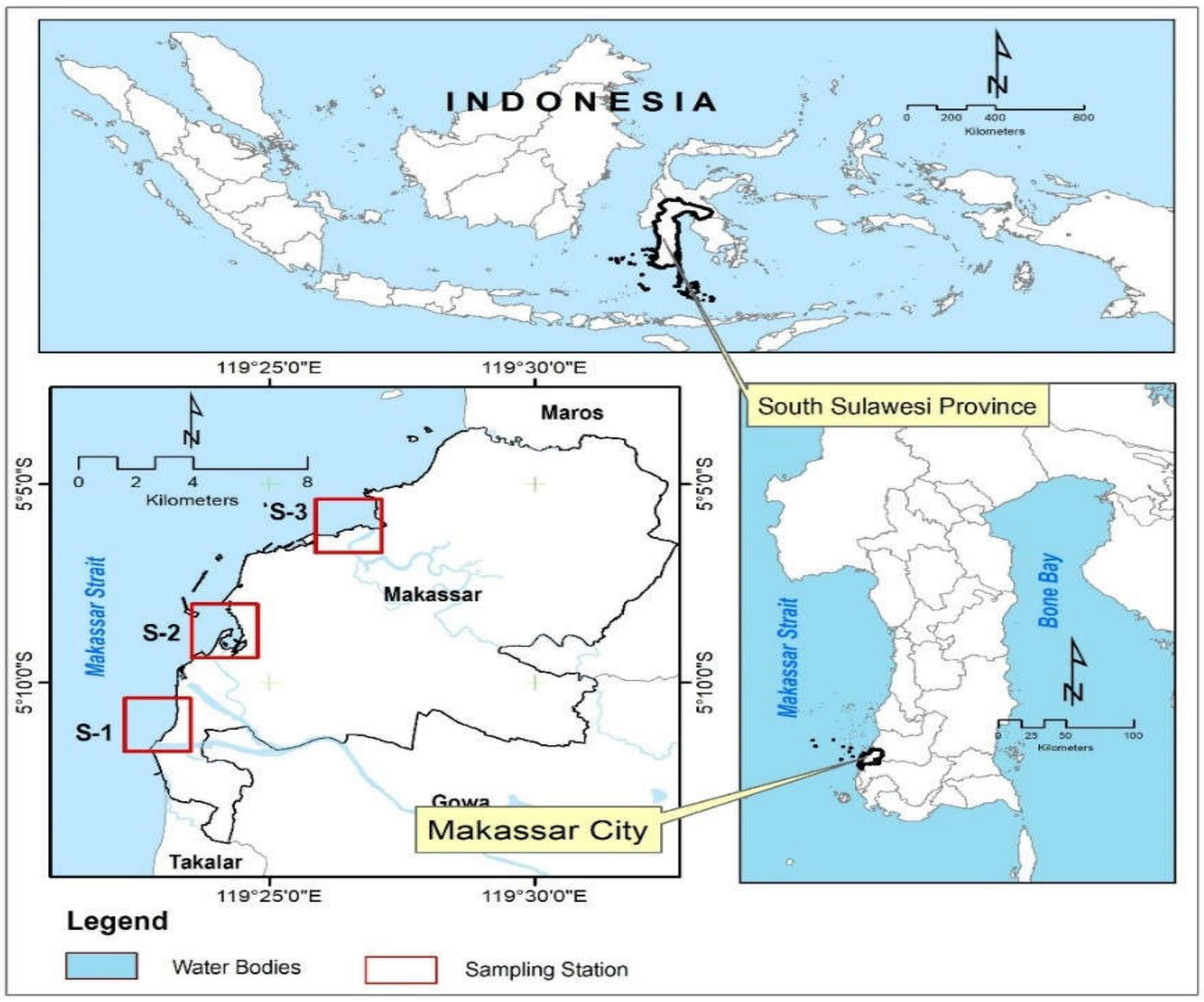

Figure 1. Makassar Coastal Water; Study area and sampling station

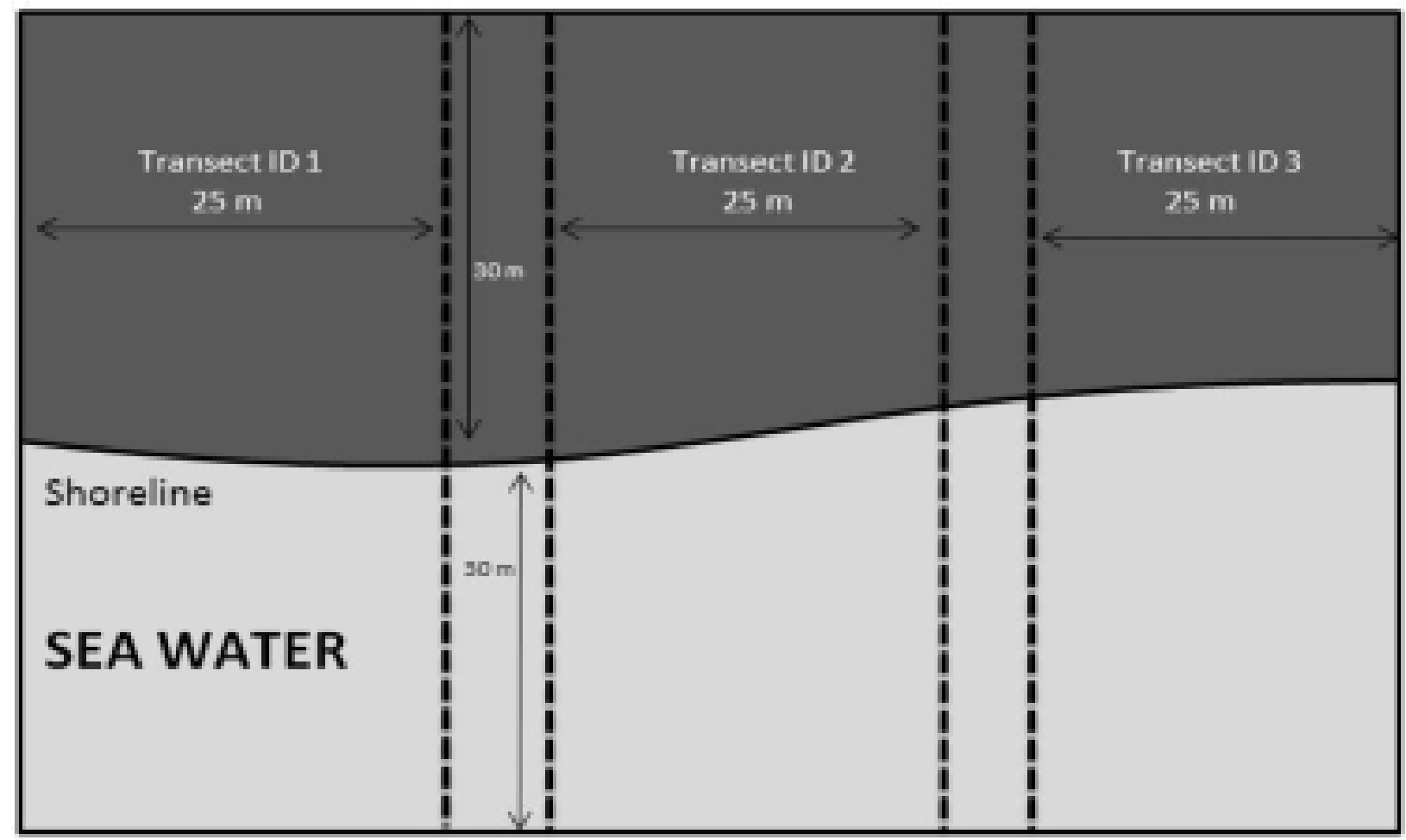

Figure 2. Layout of plastic debris collection at each location (Based on NOAA- Lippiatt et al. (2013)) 

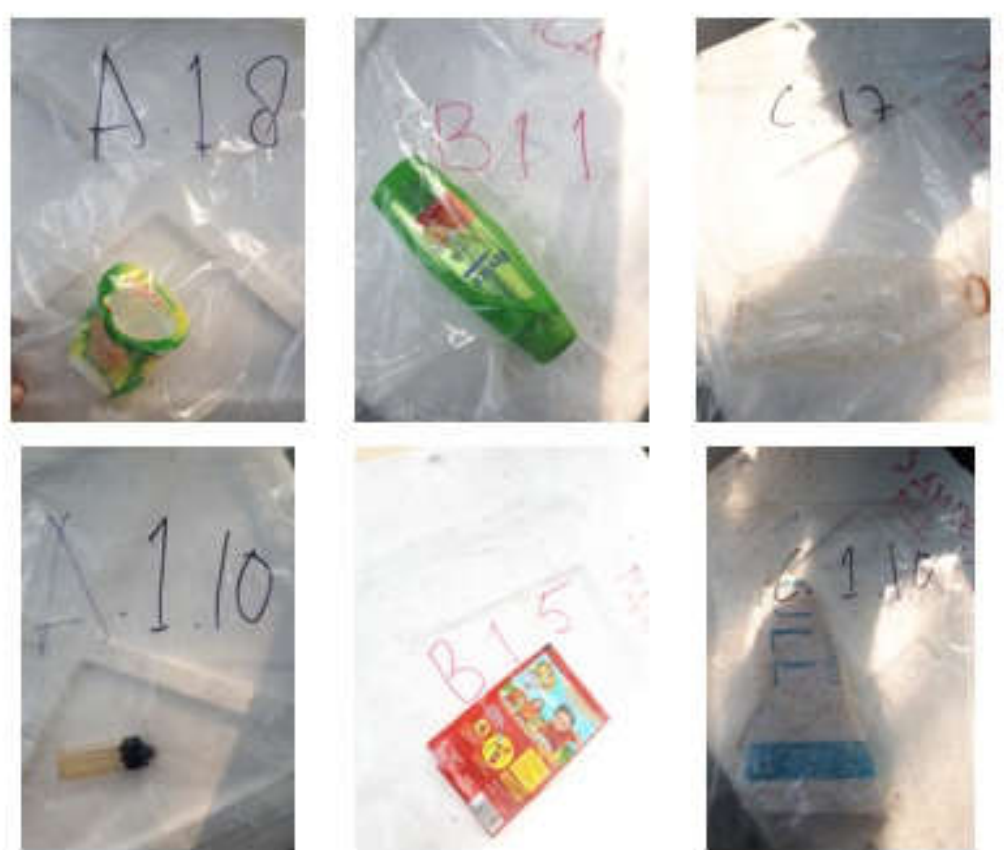

Figure 3. Some of the plastic debris collected from each station ( $\mathrm{A}=$ Station ; $\mathrm{B}=$ Station 2 ; and $\mathrm{C}=$ Station 3 ).
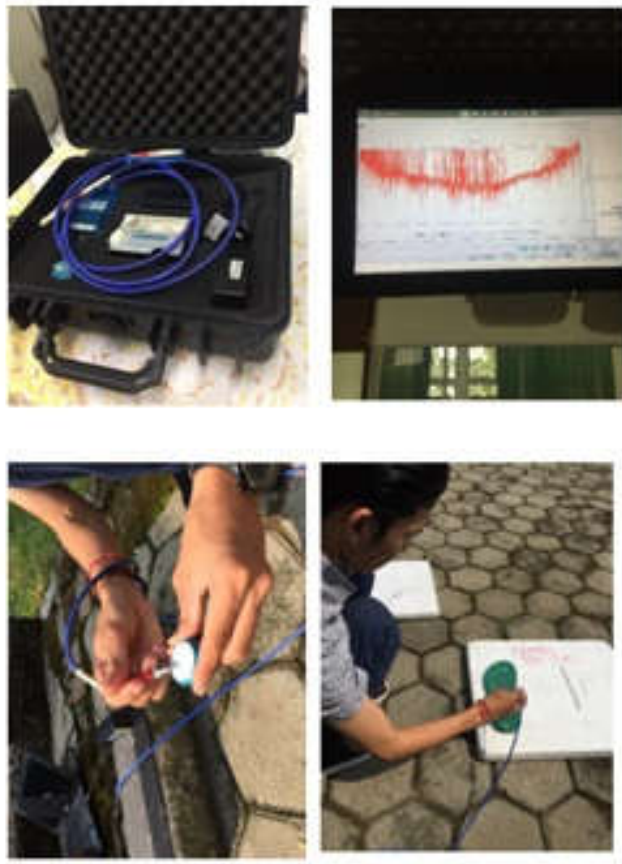

Figure 4. Spectral measurement of plastic debris using Ocean Optics USB 4000.

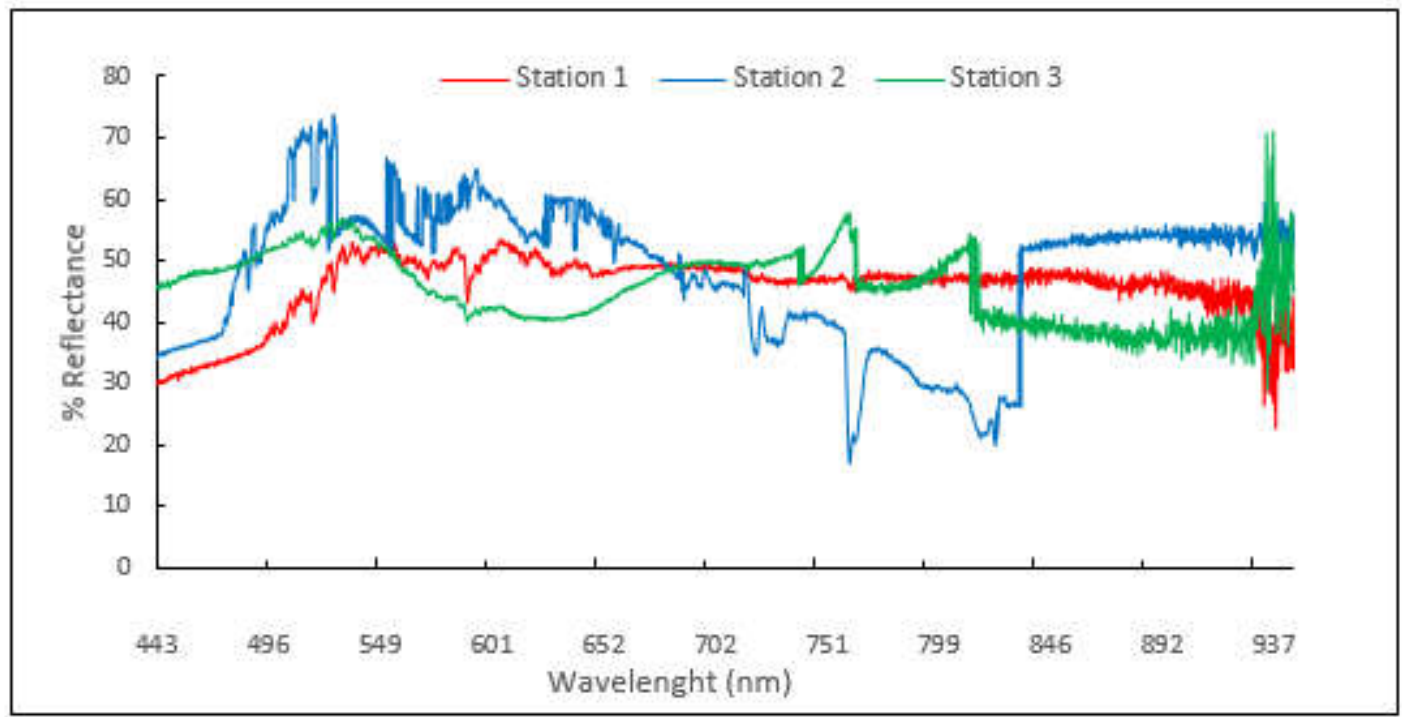

Figure 5. The average of spectral reflectance curve of plastic debris for each sample at all stations.

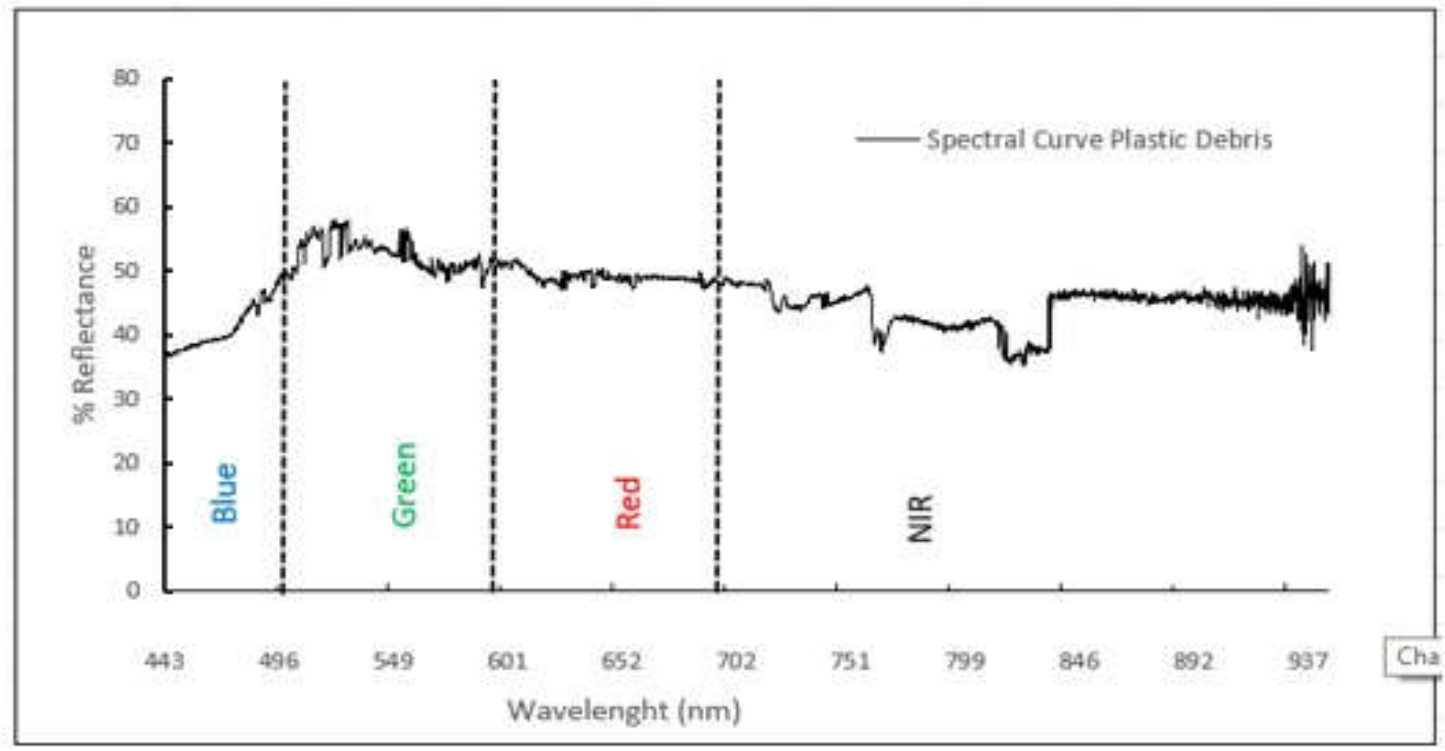

Figure 6. Comparisons of averaged spectral curve plastic debris with divisions based on wavelength. 
Table 1. The Range of plastic debris spectral reflectance on the visible (blue, green and red) and the near-infrared (NIR) wavelength. Value is the average $\pm \mathrm{SE}$

\begin{tabular}{lcccc}
\hline Sample and Reference & Blue $(450-510 \mathrm{~nm})$ & Green $(510-580 \mathrm{~nm})$ & Red $(580-670 \mathrm{~nm})$ & NIR $(670-950 \mathrm{~nm})$ \\
\hline Plastic $^{\star}$ & $41.68 \pm 4.11^{\mathrm{a}}$ & $46.08 \pm 7.59^{\mathrm{a}}$ & $47.54 \pm 4.54^{\mathrm{a}}$ & $44.41 \pm 1.35^{\mathrm{a}, \mathrm{b}}$ \\
Air-dry Sand $^{* *}$ & $20.65 \pm 0.18^{\mathrm{b}}$ & $24.94 \pm 0.40^{\mathrm{b}, \mathrm{c}}$ & $28.63 \pm 0.21^{\mathrm{b}}$ & $31.37 \pm 0.36^{\mathrm{a}, \mathrm{b}}$ \\
Wet Sand $^{* *}$ & $7.30 \pm 0.39^{\mathrm{c}}$ & $11.09 \pm 0.39^{\mathrm{b}, \mathrm{c}}$ & $11.91 \pm 0.67^{\mathrm{c}}$ & $\pm 0.19^{\mathrm{c}}$ \\
\hline
\end{tabular}

*This study

${ }^{*}$ Spectral reflectance by (Nolet et al., 2014).

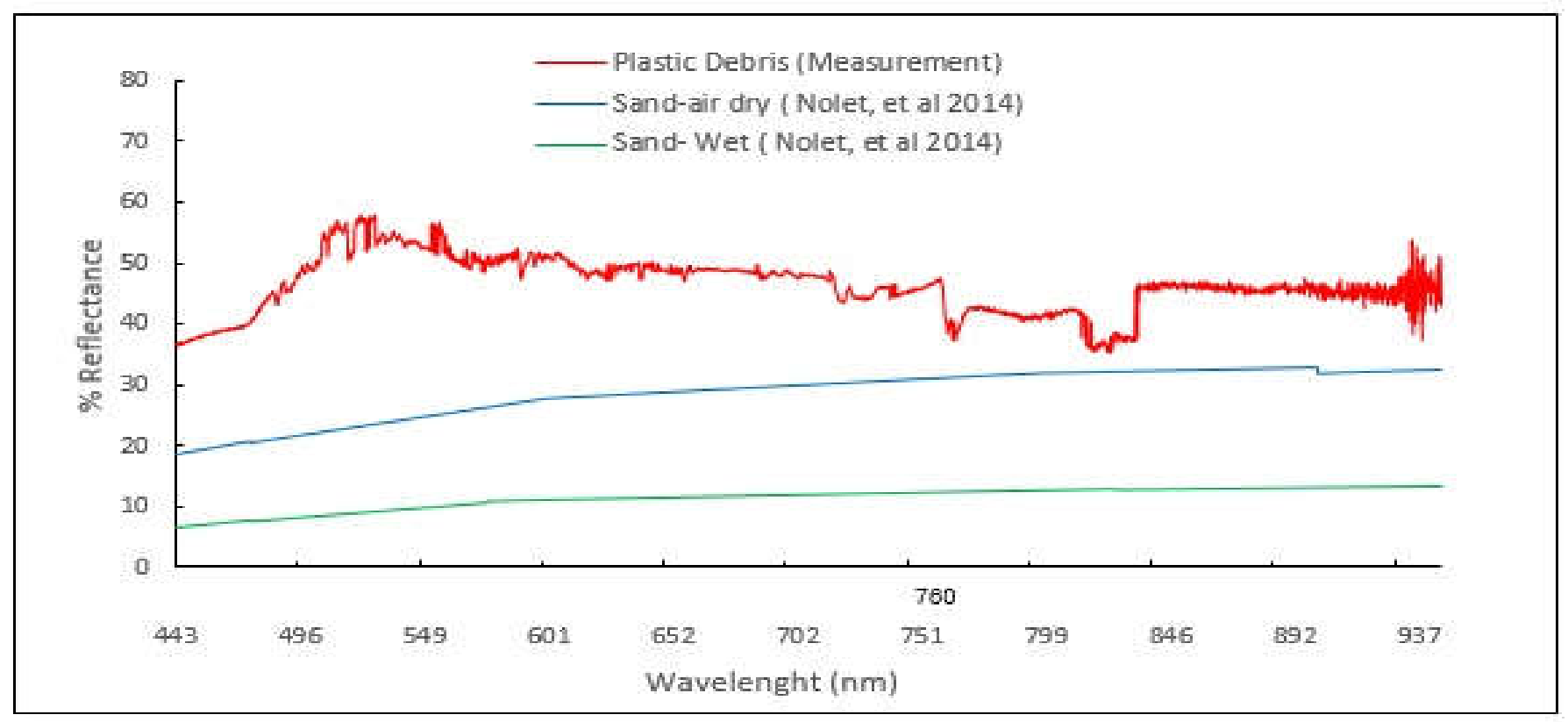

Figure 7. Comparison of the average value of plastic reflectance with sand reflectance by Nolet et al. (2014).

ylene (PE), polypropylene (PP), polyvinylchloride (PVC), polyamide (nylon) and polystyrene (PS) (Andrady, 2015).

Different chemical compositions resulted in different spectral reflectance values as well (Imhof et al., 2017). Another factor is because the found samples have been degraded and have weathered naturally or partially fragmented into microplastic (GESAMP, 2015; Shah et al., 2008; Thevenon et al., 2014). In different time and weather conditions, the sunlight's penetration that reaches to the earth's surface also varies, the number of wavelengths that reach the earth's surface or the object is affected by the amount of scattering and absorption of particles in the atmosphere (Lillesand et al., 2015; Murphy et al., 2018) (Lillesand et al., 2015; Murphy et al., 2018).

The tendency of reflectance pattern of each sample at every station (Figure 5) is almost the same, this is due to the similarity of the main chemical component of the plastic (Andrady, 2015). In several hyperspectral studies with different objects and similar main components, have similar spectral patterns, such as vegetation (Huete, 1988), coral reefs (Hochberg et al., 2003), and soil (Lillesand et al., 2015).

The spectral reflectance pattern of plastic debris found in the beach at all observation stations (Figure 6) shows various spectral values with optimum records at the wavelength of $500-700 \mathrm{~nm}$. This wavelength range includes a visible wavelength of $450670 \mathrm{~nm}$. In detail, the visible wavelength is divided into 3 wavelengths; Blue (450 - $510 \mathrm{~nm}$ ), Green (510
- $580 \mathrm{~nm})$ and Red (580 - $670 \mathrm{~nm})$. One factor that might cause differences in the spectral characteristics of each station is the presence of macroalgae that began to grow in various samples, will automatically influence the spectral reflection of each object at each station (Diaz \& Rosenberg, 1995).

The analysis of variance on the data of all stations showed no differences in the spectral characteristics of each station ( $p>0.05)$ therefore the spectral values of each station were averaged and compiled with the spectral reflectance curves from sand beach at two conditions of volumetric moisture content of $32 \%$ (wet or saturation) and $0.01 \%$ (air-dry) (Nolet et al., 2014) as in Figure 7.

\section{Conclusion}

This study aims to examine the spectral characteristics of plastic debris in the coastal area (beach) of Makassar City with a different type of exposure. Our results showed spectral characteristics of plastic debris were not different between stations. The optimal value for the identification of plastic debris in the coastal beach under conditions of the dry sandlow tide is $450-670 \mathrm{~nm}$ and the condition of the wet sandhigh tide is $450-950 \mathrm{~nm}$. This value will be a reference in the remote sensing method, especially hyperspectral classification in mapping plastic debris found in coastal areas, and will be one solution to effectively mapping plastic debris. 


\section{Acknowledgment}

This research was done with research funding from the Competency-Based Research Scheme (Penelitian Berbasis Kompetensi) with Contract Number L 1715 / UN4.21 / PL.00.00 / 2018. This research, in addition, was also carried out with the participation of Widodo, Researcher in the Laboratory of Remote Sensing and Ecology, SEAMEO Biotrop, also Sunarto and Muhammad Ilham from the Faculty of Marine and Fisheries, Hasanuddin University.

\section{References}

Andrady, A. L. (2015). Persistence of plastic litter in the oceans. In M. In: Bergmann, Gutow, L., Klages, M (Ed.), Marine Anthropogenic Litter (pp. 57-22): Springer International Publishing AG Switzerland.

Aoyama, T. (2014). Monitoring of marine debris in the sea of Japan using multi-spectral sattelite images Paper presented at the SPIE Asia-Pacific Remote Sensing.

Diaz, R., \& Rosenberg, R. (1995). Marine benthic hypoxia: A review of its ecological effects and the behavioural response of benthic macrofauna. Oceanography and Marine Biology-an Annual Review, 33(33), 245-133.

Driedger, H. Durr, K. Mitchel, J. Flannery, E. Brancazi, \& Cappelen, P. V. (2013). Plastic Debris; Remote sensing and characterization. Canada: University of Waterloo.

Flanigan, D. F., Samuels, A. C., \& Ben-David, A. (2004). Noise assessment of a Fourier transform infrared spectroradiometer subject to the stability of a conventional laboratory blackbody source. Applied Optics, 43(13), 2767-2776. doi:10.1364/AO.43.002767.

GESAMP. (2015). Sources, fate and effects of microplastics in the marine environment: Part two of a global assessment (P. J. K. a. C. M. Rochman Ed.). 4 Albert Embankment, London SE1 7SR: INTERNATIONAL MARITIME ORRGANIZATION.

Gregory, M. R. (2009). Environmental implications of plastic debris in marine settings-entanglement, ingestion, smothering, hangers-on, hitch-hiking and alien invasions. Philosophical Transactions of the Royal Society B: Biological Sciences, 364 (1526), 2013-2025. doi:doi:10.1098/rstb.2008.0265

Halma, C. (2008). USB4000 Fiber Optic Spectrometer: Instalation and Operation Manual. Retrieved from $\mathrm{w} w \mathrm{w}$. oc e a n o p t i c s.com/te ch n i a l/ USB4000OperatingInstructions.pdf.

Hochberg, E. J., Atkinson, M. J., \& Andréfouët, S. (2003). Spectral reflectance of coral reef bottom-types worldwide and implications for coral reef remote sensing. Remote Sensing of Environment, 85(2), 159-173. doi:https://doi.org/10.1016/ S0034-4257(02)00201-8.

Hörig, B., Kühn, F., Oschütz, F., \& Lehmann, F. (2001). HyMap hyperspectral remote sensing to detect hydrocarbons. International Journal of Remote Sensing, 22(8), 1413-1422. doi:10.1080/01431160120909.

Huete, A. R. (1988). A soil-adjusted vegetation index (SAVI). Remote Sensing of Environment, 25(3), 295-309. doi:https:// doi.org/10.1016/0034-4257(88)90106-X.

Imhof, H. K., Sigl, R., Brauer, E., Feyl, S., Giesemann, P., Klink, S. Leupolz, K., Löder, M. G. J., Löschel, L. A., Missun, J., Muszynski, S., Ramsperger, A. F. R. M., Schrank, I., Speck, S., Steibl, S., Trotter, B., Winter, I., \& Laforsch, C. (2017). Spatial and temporal variation of macro-, meso- and microplastic abundance on a remote coral island of the Maldives, Indian Ocean. Marine Pollution Bulletin, 116(1), 340-347. doi:https://doi.org/10.1016/j.marpolbul.2017.01.010.

Jambeck, J. R., Geyer, R., Wilcox, C., Siegler, T. R., Perryman, M., Andrady, A., Narayan, R., \& Law, K. L. (2015). Plastic waste inputs from land into the ocean. Science, 347(6223), 768771. doi:10.1126/science. 1260352.
Jensen, J. R. (2004). Introductory Digital Image Processing: A Remote Sensing Perspective.: Prentice-Hall, Inc, New York.

Krelling, A. P., Williams, A. T., \& Turra, A. (2017). Differences in perception and reaction of tourist groups to beach marine debris that can influence a loss of tourism revenue in coastal areas. Marine Policy, 85, 87-99. doi:https:// doi.org/10.1016/j.marpol.2017.08.021.

Lillesand, T., Kiefer, R. W., \& Chipman, J. (2015). Remote Sensing and Image Interpretation, 7 th Edition: Wiley.

Lippiatt, S., Opfer, S., \& Arthur, C. (2013). Marine Debris Monitoring and Assessment: NOAA Technical Memorandum NOSOR\&R-46.

Mace, T. H. (2012). At-sea detection of marine debris: Overview of technologies, processes, issues, and options. Marine Pollution Bulletin, 65(1), 23-27. doi:https://doi.org/10.1016/ j.marpolbul.2011.08.042.

Maulana, F. (2016). Identifikasi sampah laut di kawasan wisata pantai Kota Makassar. (Skripsi), Universitas Hasanuddin, Makassar.

McIlgorm, A., Campbell, H. F., \& Rule, M. J. (2011). The economic cost and control of marine debris damage in the AsiaPacific region. Ocean \& Coastal Management, 54(9), 643651. doi:https://doi.org/10.1016/j.ocecoaman.2011.05.007

Moy, K., Neilson, B., Chung, A., Meadows, A., Castrence, M., Ambagis, S., \& Davidson, K. (2018). Mapping coastal marine debris using aerial imagery and spatial analysis. Marine Pollution Bulletin, 132, 52-59. doi:https://doi.org/10.1016/ j.marpolbul.2017.11.045.

Murphy, L. G., Peters, S., van Sebille, E., James, N. A., \& Gibb, S. (2018). Concept for a hyperspectral remote sensing algorithm for floating marine macro plastics. Marine Pollution Bulletin, 126, 255-262. doi:https://doi.org/10.1016/ j.marpolbul.2017.11.011.

NOAA. (2015). Turning The Tide On Trash. A Learning Guide On Marine Debris: NOAA PIFSC CRED.

Nolet, C., Poortinga, A., Roosjen, P., Bartholomeus, H., \& Ruessink, G. (2014). Measuring and Modeling the Effect of Surface Moisture on the Spectral Reflectance of Coastal Beach Sand. PLOS ONE, 9(11), e112151. doi:10.1371/ journal.pone.0112151.

Pawar, P., Shirgaonkar, S., \& affiliations, R. (2016). Plastic marine debris: Sources, distribution and impacts on coastal and ocean biodiversity. PENCIL Publication of Biological Sciences (OCEANOGRAPHY). 3(1): 40-54. (ISSN: 2408-5561). $3,40-54$.

Pichel, W. G., Churnside, J. H., Veenstra, T. S., Foley, D. G., Friedman, K. S., Brainard, R. E., Nicoll, J. B., Zheng, Q., \& Clemente-Colón, P. (2007). Marine debris collects within the North Pacific Subtropical Convergence Zone. Marine Pollution Bulletin, 54(8), 1207-1211. doi:https:// doi.org/10.1016/j.marpolbul.2007.04.010.

SCBD-STAP-GEF. (2012). Impacts of Marine Debris on Biodiversity: Current Status and Potential Solutions. Montreal: Technical Series.

Schaepman, M. E., \& Dangel, S. (2000). Solid laboratory calibration of a nonimaging spectroradiometer. Applied Optics, 39(21), 3754-3764. doi:10.1364/AO.39.003754.

Shah, A. A., Hasan, F., Hameed, A., \& Ahmed, S. (2008). Biological degradation of plastics: A comprehensive review. Biotechnology Advances, 26(3), 246-265. doi:https:// doi.org/10.1016/j.biotechadv.2007.12.005.

Thevenon, F., Carroll, C., \& Sousa, J. (2014). Plastic Debris in the Ocean. The Characterization of Marine Plastics and their Environmental Impacts. Situation Analysis Report. Gland, Switzerland: IUCN .

Van Cauwenberghe, L., Claessens, M., Vandegehuchte, M. B., Mees, J., \& Janssen, C. R. (2013). Assessment of marine debris on the Belgian Continental Shelf. Marine Pollution Bulletin, 73 (1), 161-169. doi:https://doi.org/10.1016/ j.marpolbul.2013.05.026. 
van Franeker, J. A., \& Law, K. L. (2015). Seabirds, gyres and global trends in plastic pollution. Environmental Pollution, 203, 89-96. doi:https://doi.org/10.1016/j.envpol.2015.02.034.

Veenstra, T. S., \& Churnside, J. H. (2012). Airborne sensors for detecting large marine debris at sea. Marine Pollution Bulletin, 65(1), 63-68. doi:https://doi.org/10.1016/ j.marpolbul.2010.11.018.

Webb, H. K., Arnott, J., Crawford, R. J., \& Ivanova, E. P. (2013). Plastic Degradation and Its Environmental Implications with Special Reference to Poly(ethylene terephthalate). Polymers, 5(1), 1-18. 